The major portion of the inhibitory activity is due to a compound which is soluble in ether and other organic solvents, and unstable in aqueous solution. A small part of the total inhibitory activity is due to a compound which is poorly soluble in ether, and stable in aqueous solution at neutral and at acid $p \mathrm{H}$. It is possible that other derivatives may be formed in small amounts?. Further experiments on the separation of these compounds are being carried out.
D. K. MYeRS
J. B. J. REBEL
C. VEeger
A. KEMP
E. G. L. SIMONS

Pharmaco-therapeutic Laboratory, University of Amsterdam.

${ }^{1}$ Smith, M. I., and Lillie, R. D., Arch. Neurol. Psychiat. Chicago, 26, 976 (1931). Hottinger, A., and Bloch, H., Helv. Chim. Acta, 26, 142 (1043). Earl, C. J., and Thompson, R.'H. S., Brit. J. Pharmacol., 7, 685 (1952).

${ }^{2}$ Mendel, B., and Myers, D. K., Biochem. J., 53, xvi (1953).

${ }^{3}$ Aldridge, W. N., Biochem. J., 56, 185 (1954).

4 Gross, E., and Grosse, A., Arch. Exp. Path. Pharmakol., 168, 473 (1932).

- Myers, D. K., "Studies on Selective Esterase Inhibitors", Ph.D. thesis, Univ. Amsterdam (1954).

- Bloch, H., Helv. Chim. Acta, 26, 733 (1943).

'Bray, H. G., Lake, H. J., and Thorpe, W. V., Biochem. J., 44, 136 (1949). Parke, D. V., and Williams, R. T., Biochem. J., 59, 415 (1955).

\section{A New Difference between Live and Dead Spermatozoa}

WHen semen is diluted with a solution of formaldehyde under certain standard conditions of $p H$, temperature and osmotic pressure, dead spermatozoa are agglutinated but living ones are not. This difference between live and dead spermatozoa has been investigated in 103 ejaculates from seven bulls at a commercial insemination centre. Samples from a hundred of these ejaculates were used for insemina. tion, three ejaculates being unsuitable for insemina. tion because of low sperm motility.

The percentage of dead spermatozoa in duplicate samples of each ejacuiate was estimated in smears stained with nigrosin-eosin ${ }^{1}$. The staining solution $\left(p \mathrm{H} 7.2 ; \Delta,-0.54^{\circ} \mathrm{C} . \pm 0.02^{\circ} \mathrm{C}\right.$.) was used at $37^{\circ} \mathrm{C}$. Details of the composition of this new solution and of the buffered formal-saline used here will be published elsewhere. Duplicate samples of each ejaculate were fixed in a buffered isotonic solution of sodium chloride $\left(p \mathrm{H} 7.0 ; \Delta,-0.53^{\circ} \mathrm{C}\right.$.) with added formaldehyde (5 per cent formaldehyde), by adding one drop of semen at $37^{\circ} \mathrm{C}$. to each of two tubes containing $3 \mathrm{ml}$. fixative also at $37^{\circ} \mathrm{C}$. After fifteen minutes incubation at $37^{\circ} \mathrm{C}$., the samples were allowed to cool to room temperature.

Measurements of the percentage of dead (eosinophil) spermatozoa and of the degree of agglutination were made after a variable period (up to two weeks), following treatment of the sample. The number of dead spermatozoa in a total of a hundred was counted on each of two slides. The degree of agglutination was scored on a unit scale of 1 (minimal agglutination) to 4 (maximal agglutination). The samples were shaken and scored by visual assessment of agglutination using transmitted light. The percentage dead and the agglutination score were estimated independently by different observers.

The relationship between percentage dead spermatozoa and agglutination score was examined by regression analysis. The mean percentage dead spermatozoa was used as one variable, and the combined agglutination scores for each sample pair as the second variable. The analysis was made by Dr. R. C. Campbell, Agricultural Research Council Unit of Reproductive Physiology and Biochemistry, Cambridge.

A highly significant relationship $(p<0.001)$ was found between percentage dead spermatozoa and agglutination score. The mean percentage of dead spermatozoa for all samples was $\mathbf{1 6} \cdot 7$ (range $3 \cdot 5-65 \cdot 0$ ) ; the mean agglutination seore for all samples was $3 \cdot 4$ (range 2-8). The mean percentages of dead spermatozoa in the three ejaculates discarded as unfit for insemination were $65 \cdot 0,40 \cdot 0$ and 39.5 ; the combined agglutination scores were 8,6 and 6 .

This difference between living and dead cells does not seem to have been noted before and it may therefore be of some fundamental interest; but, at the moment, we are more concerned with the following practical implications. In 103 samples of bull semen which, with three exceptions, were judged to be suitable for insemination, there was a pronounced relationship between the proportion of dead spermatozoa and the degree of agglutination after treatment of the semen with formaldehyde. A relationship is known to exist between the fertilizing capacity of bull semen and its content of dead spermatozoa ${ }^{2}$; the agglutinability of spermatozoa by formaldehyde may therefore be a simple and useful criterion of the fertilizing capacity of bull semen.

We wish to thank Dr. R. Aschaffenburg, National Institute for Research in Dairying, Reading, and Lord Rothschild, Department of Zoology, University of Cambridge, for measurements of the freezing points of some of the reagents used, and Mr. J. A. Moss, Avoncroft Cattle Breeders, Ltd., for facilities.

\section{J. L. HANCOCK}

Agricultural Research Council Institute of Animal Physiology,

Babraham, Cambridge.

Ministry of Agriculture

I. G. SHAW

Veterinary Investigation Service, Bromsgrove.

March 23.

1 Campbell, R. C., Hancock, J. L., and Rothschild, Lord, J. Exp. Biol., 30,44 (1953).

${ }^{2}$ Bishop, M. W. H., Campbell, R. C., Hancock, J. L., and Walton, A., J. Agric. Sci., 44, 227 (1954).

\section{Biochemical Mutations in the Crucifer Arabidopsis thaliana (L.) Heynh.}

THE photosynthetic flowering plants possess a greater capacity for synthesis of crystalloids than any other group of organisms. Their complete exogenous requirements for growth consist of only fourteen elements and the two compounds carbon dioxide and water. No intact flowering plant, with the exception of those lacking chlorophyll, has been shown to require any organic compound apart, of course, from carbon dioxide. I have now attempted to examine plant biosynthesis by the 'mutational block' method, which has been of great success in the analysis of metabolism in haploid micro-organisms.

Selection of mutants deficient in essential syntheses can only be carried out satisfactorily under aseptic conditions, so a necessary prerequisite is an adequate method for the sterile culture of higher plants. In this respect the suitability of the experimental plant 